\title{
Alternative Splicing of an Insect Sodium Channel Gene Generates Pharmacologically Distinct Sodium Channels
}

\author{
Jianguo Tan, ${ }^{1 *}$ Zhiqi Liu, ${ }^{1 *}$ Yoshiko Nomura, ${ }^{1}$ Alan L. Goldin, ${ }^{2}$ and Ke Dong ${ }^{1}$ \\ ${ }^{1}$ Department of Entomology and Neuroscience Program, Michigan State University, East Lansing, Michigan 48824, and \\ 2Department of Microbiology and Molecular Genetics, University of California, Irvine, California 92697
}

\begin{abstract}
Alternative splicing is a major mechanism by which potassium and calcium channels increase functional diversity in animals. Extensive alternative splicing of the para sodium channel gene and developmental regulation of alternative splicing have been reported in Drosophila species. Alternative splicing has also been observed for several mammalian voltage-gated sodium channel genes. However, the functional significance of alternative splicing of sodium channels has not been demonstrated. In this study, we identified three mutually exclusive alternative exons encoding part of segments 3 and 4 of domain III in the German cockroach sodium channel gene, para ${ }^{C S M A}$. The splice site is conserved in the mouse, fish, and human $\mathrm{Na}_{v} 1.6$ sodium channel genes, suggesting an ancient origin. One of the alternative exons possesses a stop codon, which would generate a truncated protein with only the first two domains. The splicing
\end{abstract}

variant containing the stop codon is detected only in the PNS, whereas the other two full-size variants were detected in both the PNS and CNS. When expressed in Xenopus oocytes, the two splicing variants produced robust sodium currents, but with different gating properties, whereas the splicing variant with the stop codon did not produce any detectable sodium current. Furthermore, these two functional splicing variants exhibited a striking difference in sensitivity to a pyrethroid insecticide, deltamethrin. Exon swapping partially reversed the channel sensitivity to deltamethrin. Our results therefore provide the first evidence that alternative splicing of a sodium channel gene produces pharmacologically distinct channels.

Key words: alternative splicing; para; paraCSMA; sodium channel; pyrethroid insecticide; Xenopus oocyte expression system
Voltage-gated sodium channels are responsible for the rising phase of action potentials in the membranes of neurons and most electrically excitable cells (Catterall, 2000). Mammalian sodium channels consist of a pore-forming $\alpha$-subunit of $\sim 260 \mathrm{kDa}$ and one or two accessory $\beta$-subunits of $33-36 \mathrm{kDa}$. In the last two decades, 10 different mammalian sodium channel $\alpha$-subunit genes have been isolated (Goldin, 2001). In Drosophila melanogaster, two sodium channel genes, para and DSC1, have been identified, but para is the only one that has been shown to encode a functional sodium channel (Salkoff et al., 1987; Loughney et al., 1989; Feng et al., 1995; Warmke et al., 1997). The overall organization of sodium channel proteins is conserved among invertebrates and vertebrates and consists of four homologous domains (I-IV), each containing six transmembrane segments (S1-S6) (see Fig. 1A).

Alternative splicing is a key mechanism for generating structural and functional diversity of many membrane proteins, including potassium and calcium channels. For example, alternatively spliced variants of Drosophila Shaker $\mathrm{K}^{+}$channel exhibit distinct activation and inactivation rates (Iverson et al., 1988; Timpe et al., 1988). Splice variants of the N-type calcium channel differ in channel gating kinetics and also exhibit unique expression pat-

\footnotetext{
Received Nov. 27, 2001; revised April 11, 2002; accepted April 15, 2002.

This work was supported in part by National Science Foundation Grants IBN 9696092 and IBN 9808156 (K.D). We thank N. Koller for critical review of this manuscript. We also thank the anonymous reviewers for their critical comments and suggestions.

*J.T. and Z.L. contributed equally to this project.

Correspondence should be addressed to Ke Dong, Center for Integrated Plant Systems, Room 106, Michigan State University, East Lansing, MI 48824. E-mail: dongk@pilot.msu.edu.

Copyright (C) 2002 Society for Neuroscience $\quad 0270-6474 / 02 / 220001-10 \$ 15.00 / 0$
}

terns in brain and peripheral ganglia (Lin et al., 1997). Splicing of the $\alpha 1 \mathrm{~A}$ subunit gene generates phenotypic variants of $\mathrm{P}-$ and Q-type $\mathrm{Ca}^{2+}$ channels (Bourinet et al., 1999). Vertebrate and invertebrate sodium channel genes are also extensively spliced, but very little is known about whether alternative splicing contributes to sodium channel diversity. Only one study has reported a presumed splice variant of the rat Nav1.6 (PN4) sodium channel exhibiting faster recovery from inactivation (Dietrich et al., 1998).

The current literature suggests that functional diversity of sodium channels in mammals is achieved mainly by expression of distinct sodium channel genes. The mammalian sodium channel isoforms exhibit unique tissue distributions, channel properties, and distinct pharmacology (Goldin, 2001). Nevertheless, a functional role for alternative splicing is implicated by the conservation of several identified alternative splice sites in mammalian and insect sodium channel genes. For example, two mutually exclusive alternative exons encoding IS3-4 are conserved in both Nav1.2 (type II) and Nav1.3 (type III) rat brain sodium channel genes (Sarao et al., 1991; Gustafson et al., 1993). Two other alternatively spliced exons, $18 \mathrm{~N}$ and $18 \mathrm{~A}$, encoding IIIS3-4 of the mouse sodium channel Nav1.6 (SCN8A), were identified in fish and human sodium channel genes (Plummer et al., 1997). Inclusion or exclusion of short segments in the intracellular linker connecting domains I and II was observed in all three rat sodium channel genes (Schaller et al., 1992; Belcher et al., 1995). Even more extensive alternative splicing was found in the para gene of $D$. melanogaster. A total of nine alternatively spliced exons have been identified, with seven exons $(a, i, b, e, f, j$, and $h)$ in the first or second intracellular linker, and two mutually exclusive exons, $c$ or $d$, in domain II (Loughney et al., 1989; Thackeray and Ganetzky, 1994; O’Dowd et al., 1995). The actual number of para splice sites 
may well be much larger than nine, because the region examined in detail in these studies represents only $\sim 30 \%$ of the complete para open reading frame. Significantly, these alternative splice sites are conserved in D. virilis (Thackeray and Ganetzky, 1995), which diverged from D. melanogaster 44-60 million years ago.

Although insects appear to have only one functional sodium channel gene (e.g., para in D. melanogaster), the existence of sodium channel functional diversity has been reported in cultured insect neurons. For example, fast and completely inactivating sodium currents were observed in some D. melanogaster neurons, whereas other neurons exhibited a non-inactivating component (Saito and $\mathrm{Wu}, 1991)$. In addition, there is significant variation in the amplitude of peak current in Drosophila embryonic neurons (Byerly and Leung, 1988). Similarly, early electrophysiological studies show that pyrethroid insecticides affect the insect PNS, e.g., sensory neurons, more effectively than the CNS (Burt and Goodchild, 1971; Miller and Adams, 1977; Osborne and Hart, 1979; Salgado et al., 1983; Roche and Guillet , 1985), suggesting the existence of distinct types of sodium channels. The molecular basis of this diversity, however, is not understood.

In this study, we identified three alternatively spliced exons in the IIIS3-4 region of the German cockroach para ${ }^{\text {CSMA }}$ gene. These alternative exons have previously been found in fish, mouse, and human sodium channel genes. The discovery of these alternative exons in an insect suggests the ancient origin and conserved function of these splicing events during sodium channel evolution. We isolated three full-length cDNA clones, each containing one of the three alternative exons. Functional expression of two splicing variants in Xenopus oocytes revealed different gating properties and greatly different sensitivities to a pyrethroid insecticide, deltamethrin, providing direct evidence that alternative splicing produces pharmacologically distinct sodium channels.

\section{MATERIALS AND METHODS}

Cockroaches and tissues. Various tissues were isolated from an insecticide-susceptible German cockroach strain (CSMA; generously provided by Dr. J. G. Scott, Cornell University, Ithaca, NY). Cockroach development was divided into six stages: embryonic stages I, II, and III, nymph stages I and II, and adult. Cockroaches in embryonic stage I had uniform yolk and no obvious segmentation; in stage II they had segmentation in abdomen and legs but no eye coloration; and in stage III they had very distinct eye color and well formed appendages and antennas. These three embryonic stages correspond to stages 1-5, stages 6-12, and stages 16-18, respectively, defined by Bell (1981). The first and second nymphal instars were designated as nymph I, and the last instar (sixth) was designated as nymph II. Ovary, gut, and nerve cord tissues were isolated from adult female cockroaches. Because the cockroach coxa, the basal segment of the leg, is rich in muscle but sparsely decorated with sensory organs, we isolated the coxa designated as leg 1 . The rest of the leg, which is more densely decorated with sensory organs, was designated as leg 2. Nerve cords include thoracic ganglia, abdominal ganglia, and the connectives.

cDNA synthesis, RT-PCR, and cloning of three full-length para cDNAs. Total RNA or mRNA was isolated from various tissues and developmental stages using a Promega RNA isolation kit (Promega, Madison, WI). The nucleotide sequence of the cockroach para ${ }^{C S M A}$ coding region was determined previously by sequencing overlapping partial cDNA clones (Dong, 1997). First-strand cDNA was synthesized from total RNA (5 $\mu \mathrm{g})$ using gene-specific primers and SuperScript II RNase H-reverse transcriptase (Invitrogen, Rockville, MD). The PCR mix $(50 \mu \mathrm{l})$ contained 1 $\mu \mathrm{l}$ of first-stand cDNA (from a total of $20 \mu \mathrm{l}$ of first-strand cDNA synthesis reaction mixture), $50 \mathrm{pmol}$ of each primer, $200 \mu \mathrm{M}$ each dNTP, $1.5 \mathrm{mM} \mathrm{MgCl}_{2}$, and $2.5 \mathrm{U}$ Taq polymerase (Invitrogen). PCR was started by addition of polymerase at high temperature $\left(94^{\circ} \mathrm{C}\right)$ before cycling. The PCR conditions were as follows: 30 cycles of $30 \mathrm{sec}$ at $94^{\circ} \mathrm{C}, 30 \mathrm{sec}$ at $58^{\circ} \mathrm{C}$, and $1 \mathrm{~min}$ at $72^{\circ} \mathrm{C}$. For each tissue or developmental stage, we repeated the RT-PCR analysis three times, each starting with RNA isolation. As a control, we also amplified a 480 bp fragment of a German cockroach actin cDNA (GenBank accession number AY004248) using primers 17 and 18 and equal amounts of total RNA (5 $\mu \mathrm{g})$ from various tissues and developmental stages. The nucleotide sequences of PCR primers used in this study are presented in Table 1.

For amplification of para ${ }^{C S M A}$, the first-strand cDNA was synthesized using mRNA isolated from heads and thoraces and primer 14, which corresponds to the sequence in the $3^{\prime}$ untranslated region. The entire coding region $(6 \mathrm{~kb})$ of para ${ }^{C S M A}$ was amplified by PCR using the eLONGase enzyme mix (Invitrogen). The amplification reaction mixture $(50 \mu \mathrm{l})$ contained $0.5 \mu \mathrm{l}$ of cDNA (from a total of $20 \mu \mathrm{l}$ of first-strand cDNA synthesis reaction mixture), 50 pmol of primer 15,50 pmol of primer 16, $200 \mu \mathrm{M}$ each dNTP, $1 \mathrm{U}$ eLONGase, $1.5 \mathrm{mM} \mathrm{MgCl}_{2}$, and $1 \times$ PCR reaction buffer supplied by the manufacturer. To facilitate cloning, $K p n \mathrm{I}$ and $\mathrm{Bam} \mathrm{H} 1$ restriction site sequences were added to primer 15 and primer 16, respectively. The sequence of primer 15 was designed to conform to the Kozak sequence for high-efficiency translation. The $\mathrm{T}^{+4}$ to $\mathrm{G}^{+4}$ change resulted in a Ser to Ala substitution. The PCR amplification was performed for 30 cycles of $30 \mathrm{sec}$ at $94^{\circ} \mathrm{C}, 30 \mathrm{sec}$ at $58^{\circ} \mathrm{C}$, and $7 \mathrm{~min}$ at $68^{\circ} \mathrm{C}$ followed by incubation at $68^{\circ} \mathrm{C}$ for $10 \mathrm{~min}$. The amplified full-length cDNA with KpnI and Bam H1 sites attached to the 5' and $3^{\prime}$ ends, respectively, was cloned into pGH19 (kindly provided by Dr. B. Ganetzky, University of Wisconsin, Madison, WI).

PCR-amplification of genomic DNA. Genomic DNA was isolated using the protocol described by Dong and Scott (1994). Amplification of genomic DNA was performed in a $50 \mu \mathrm{l}$ PCR mix containing $0.2 \mu \mathrm{g}$ of genomic DNA, $50 \mathrm{pmol}$ of each primer, $200 \mu \mathrm{M}$ each $\mathrm{dNTP}$, and $1 \mathrm{U}$ eLONGase (Invitrogen). The PCR conditions were 30 cycles of $30 \mathrm{sec}$ at $94^{\circ} \mathrm{C}, 30 \mathrm{sec}$ at $58^{\circ} \mathrm{C}$, and $10 \mathrm{~min}$ at $68^{\circ} \mathrm{C}$. The Prep-A-Gene kit (Bio-Rad, Hercules, CA) was used to isolate the PCR products from agarose gel for cloning or direct sequencing. The DNA sequence was determined in the W. M. Keck Laboratory at Yale University.

Site-directed mutagenesis and exon swapping. To perform the swapping of alternative exons G1 and G2 encoding the IIIS3-4 region between KD1 and KD2, we first introduced the $A v r I I$ and $M l u I$ sites in both KD1 and KD2 flanking the IIIS3-4 region. For this purpose, a $1.4 \mathrm{~kb}$ Eco47III fragment from KD1 and KD2 was cloned into pAlter-1 for site-directed mutagenesis (Promega). T3987 was mutated to A generating an AvrII site (underlined): GGCTAGCCCTT ${ }^{3987}$ GGTTTCAAAAAA $\rightarrow$ GGCTAGCCCTA $^{3987}$ G-GTTTCAAAAAA. T4179 was mutated to G generating an MluI site (underlined): GTGGTGAACGCT ${ }^{4179}$ TTGGTGCA- $^{-}$ AGC $\rightarrow$ GTGGTGAACGCG ${ }^{4179}$ TTGGTGCAAGC. These nucleotide changes did not result in amino acid changes. The corresponding AvrII$M l u I$ fragments containing exon G1 from KD1, and exon G2 from KD2, were then swapped to produce two chimeric constructs: KD1-G2 and KD2-G1.

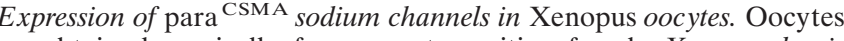
were obtained surgically from oocyte-positive female Xenopus laevis (Nasco, Ft. Atkinson, WI) and incubated with $1 \mathrm{mg} / \mathrm{ml}$ type IA collagenase (Sigma, St. Louis, MO) in $\mathrm{Ca}^{2+}$-free ND 96 medium, which contains $96 \mathrm{~mm} \mathrm{NaCl}, 2 \mathrm{~mm} \mathrm{KCl}, 1 \mathrm{~mm} \mathrm{MgCl}_{2}$, and $5 \mathrm{~mm} \mathrm{HEPES}, \mathrm{pH}$ 7.5. Follicle cells remaining on the oocytes were removed with forceps. Isolated oocytes were incubated in ND-96 medium containing $1.8 \mathrm{~mm}$ $\mathrm{CaCl}_{2}$ supplemented with $50 \mu \mathrm{g} / \mathrm{ml}$ gentamicin, $5 \mathrm{~mm}$ pyruvate, and 0.5 mM theophylline (Goldin, 1992). Healthy stage V-VI oocytes were used for cRNA injection. To prepare cRNA for oocyte injection, plasmid DNA of the para CSMA construct was linearized with Not I, which does not cut the insert, followed by in vitro transcription with $\mathrm{T} 7$ polymerase using the mMESSAGE mMACHINE kit (Ambion, Austin, TX). For the robust expression of the cockroach para ${ }^{\operatorname{CSMA}}$ sodium channel, para ${ }^{\text {CSMA }}$ cRNA (1 ng) was coinjected into oocytes with tipE cRNA (1 ng), which is known to enhance the expression of insect sodium channels in oocytes (Feng et al., 1995; Warmke et al., 1997).

Electrophysiological recording and analysis. Methods for electrophysiological recording and data analysis are similar to those described previously (Kontis and Goldin, 1993). Sodium currents were recorded using standard two-electrode voltage clamping. The borosilicate glass electrodes were filled with filtered $3 \mathrm{M} \mathrm{KCl}$ in $0.5 \%$ agarose and had resistance $<1.0 \mathrm{M} \Omega$. Currents were measured using the oocyte clamp instrument OC725C (Warner Instrument Corp., Hamden, CT), Digidata 1200A interface (Axon Instrument, Foster City, CA), and pCLAMP 6 software (Axon Instrument). All experiments were performed at room temperature $\left(20-22^{\circ} \mathrm{C}\right)$. Capacitive transient and linear leak currents were corrected using $\mathrm{P} / \mathrm{N}$ subtraction or by subtraction of records obtained in the presence of $20 \mathrm{~nm}$ tetrodotoxin (TTX), which completely blocks the Para ${ }^{\text {CSMA }}$ sodium channel (Tan et al., 2002). 
The voltage dependence of sodium channel conductance $(G)$ was calculated by measuring the peak current at test potentials ranging from $-120 \mathrm{mV}$ to $+60 \mathrm{mV}$ in $5 \mathrm{mV}$ increments and dividing by $\left(V-V_{\text {rev }}\right)$, where $V$ is the test potential and $V_{\text {rev }}$ is the reversal potential for sodium. Reversal potentials were determined from the $I-V$ curves. Peak conductance values were fitted with a two-state Boltzmann equation of the form $G=1-\left[1+\exp \left(V-V_{1 / 2}\right) / k\right]^{-1}$, in which $V$ is the potential of the voltage pulse, $V_{1 / 2}$ is the half-maximal voltage for activation, and $k$ is the slope factor.

The voltage dependence of sodium channel inactivation was determined using $200 \mathrm{msec}$ inactivating prepulses from a holding potential of $-120 \mathrm{mV}$ to $+40 \mathrm{mV}$ in $5 \mathrm{mV}$ increments, followed by test pulses to -5 $\mathrm{mV}$ for $12 \mathrm{msec}$. The peak current amplitude during the test depolarization was normalized to the maximum current amplitude and plotted as a function of the prepulse potential. The data were fitted with a two-state Boltzmann equation of the form $I=I_{\max } \times[1+(\exp (V-$ $\left.\left.\left.V_{1 / 2}\right) / k\right)\right]^{-1}$, in which $I_{\max }$ is the maximal current evoked, $V$ is the potential of the voltage pulse, $V_{1 / 2}$ is the voltage at which $50 \%$ of the current is inactivated (the midpoint of the inactivation curve), and $k$ is the slope factor. The percentage of channels modified by deltamethrin was calculated using the equation $M=\left\{\left[I_{\text {tail }} /\left(E_{\mathrm{h}}-E_{\mathrm{Na}}\right)\right] /\left[I_{\mathrm{Na}} /\left(\mathrm{E}_{\mathrm{t}}-\right.\right.\right.$ $\left.\left.\left.E_{\mathrm{Na}}\right)\right]\right\} \times 100$ (Tatebayashi and Narahashi 1994), in which $I_{\text {tail }}$ is the maximal tail current amplitude, $E_{\mathrm{h}}$ is the potential to which the membrane is repolarized, $E_{\mathrm{Na}}$ is the reversal potential for sodium current determined from the $I-V$ curve, $I_{\mathrm{Na}}$ is the amplitude of the peak current during depolarization before deltamethrin exposure, and $E_{\mathrm{t}}$ is the potential of step depolarization. The concentration-response data were fitted to the Hill equation: $M=M_{\max } /\left\{1+\left(\mathrm{EC}_{50} /[\text { deltamethrin }]\right)^{\mathrm{n}}\right\}$, in which [deltamethrin] represents the concentration of deltamethrin and $\mathrm{EC}_{50}$ represents the concentration of deltamethrin that produced the half-maximal effect, $\mathrm{n}$ represents the Hill coefficient, and $M_{\max }$ is the maximal percentage of sodium channels modified.

Deltamethrin sensitivity assay. Pyrethroids inhibit both sodium channel deactivation and inactivation resulting in large tail current after repolarization (Narahashi, 1988). Previously, Cohen and associates (Vais et al., 2000) showed that a more pronounced tail current was elicited during a 100-pulse train of $5 \mathrm{msec}$ depolarization from -120 to $0 \mathrm{mV}$ with a 5 msec interpulse interval than during a single $500 \mathrm{msec}$ depolarization to $0 \mathrm{mV}$, suggesting that deltamethrin interacts with the open state of the Para sodium channel. Therefore, we chose to use a 100-pulse train of 5 msec depolarizations to measure tail currents in this study. For application of deltamethrin, the disposable perfusion system developed by Tatebayashi and Narahashi (1994) was used. The test solution was transferred into a Petri dish placed on a support stand. Two glass capillary tubes $(10 \mathrm{~cm}$ in length) connected together with a short length of Tygon tubing were used to aid solution flow from the Petri dish to the recording chamber. The solution flow was controlled by hydrostatic force created by adjusting the level of the Petri dish relative to the recording chamber. Disposable recording chambers (1-1.5 ml volume) were made with glue dams in the Petri dish. Because deltamethrin is extremely lipophilic, recording chambers, perfusion system, and the glass agarose bridges connecting the oocyte chamber with the ground electrode chamber were all discarded after a single use. The deltamethrin stock solution $(100 \mathrm{~mm})$ was prepared in dimethylsulfoxide. The working solutions were made in ND-96 medium immediately before use. Effects of deltamethrin on sodium channel tail currents reached a steady-state level within 5 min after perfusion.

\section{RESULTS}

\section{Analysis of cDNA clones reveals possible alternative splicing of the cockroach para ${ }^{C S M A}$ gene}

Alternative splicing of para ${ }^{C S M A}$ was initially suggested from an analysis of partial cDNA clones encoding domain III. Restriction enzyme digestion analysis of 24 clones using EcoRI and BglI showed that the majority of clones shared the same digestion pattern. However, two clones had unique restriction digestion patterns suggesting sequence polymorphisms. Subsequent sequencing of the inserts of three representative clones (named clones 1,2 , and 3 ) confirmed the results of the restriction digestion analysis and revealed clustered sequence differences in a region $(<150 \mathrm{bp})$ encoding segments $3-4$ of domain III. The nucleotide and amino acid sequences of clone 1 (Fig. 1B) are

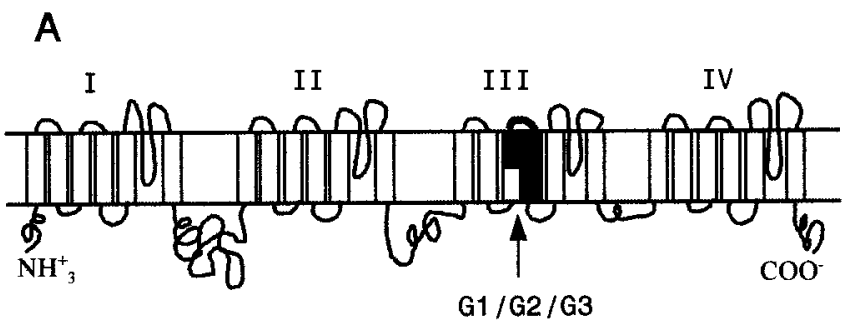

B
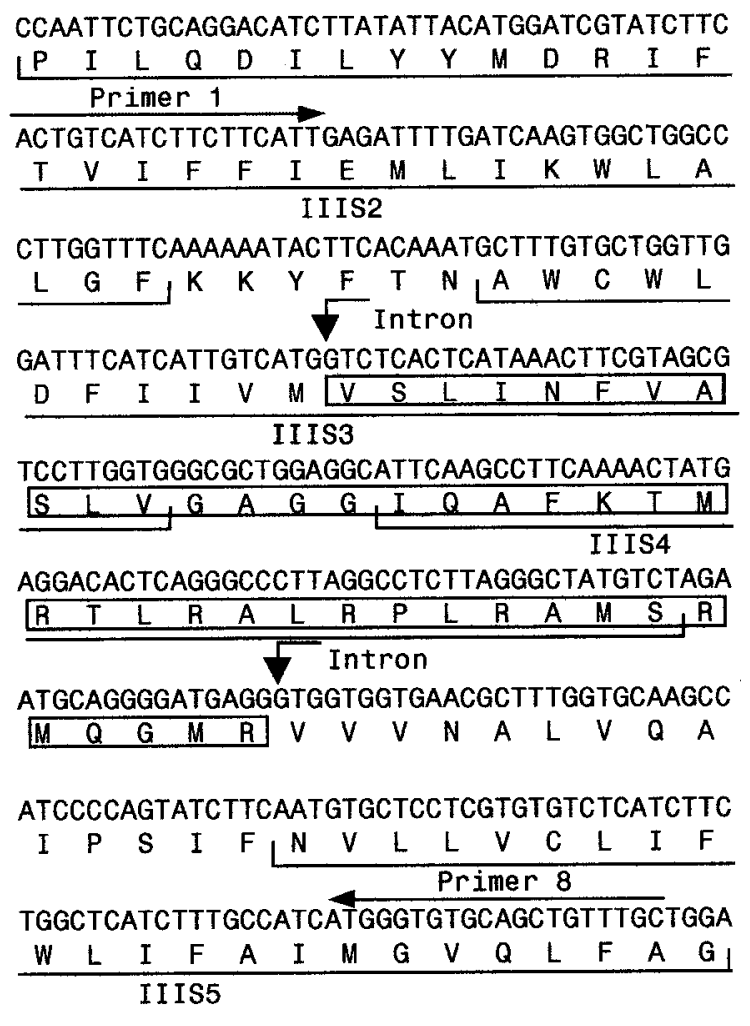

Clone \#1 VSLINFVASLVGAGGIQAFKTMRTLRALRPLRAMSRMQGMR

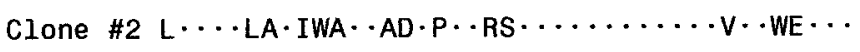

Clone \#3 EPISSDIYKLEARSEFYKN*YNKL

Figure 1. Alternatively spliced variants of the cockroach para CSMA sodium channel gene. $A$, The schematic diagram of the cockroach sodium channel topology indicating four homologous domains (I-IV), each with six transmembrane segments. The location of three mutually exclusive alternative exons G1/G2/G3 (Fig. 2) is indicated. B, Nucleotide and predicted amino acid sequences of clone 1 encoding IIIS2-5. The amino acid sequence of the variable region in clone 1 (containing exon G1) is boxed. Positions of PCR primers 1 and 8 are indicated above the sequence. $C$, Alignment of amino acid sequences of the variable region of the three clones. Dots in Clone \#2 sequence represent amino acid residues identical to those in Clone \#1. The in-frame stop codon in Clone \#3 sequence is indicated with an asterisk. The nucleotide sequences of the variable region in clones 2 and 3 are available in GenBank under accession numbers AF478702 and AF478703.

identical to the previously reported sequences (Dong, 1997). There were 14 amino acid differences between clones 1 and 2 in a stretch of 41 amino acids (Fig. 1C). However, the positively charged amino acids in S4 that serve as voltage sensors are conserved in these two clones. Clone 3 contained a unique $74 \mathrm{bp}$ sequence, which has no sequence similarity with the variable region of clone 1 or 2 (Fig. $1 C$ ). Intriguingly, the variable region 


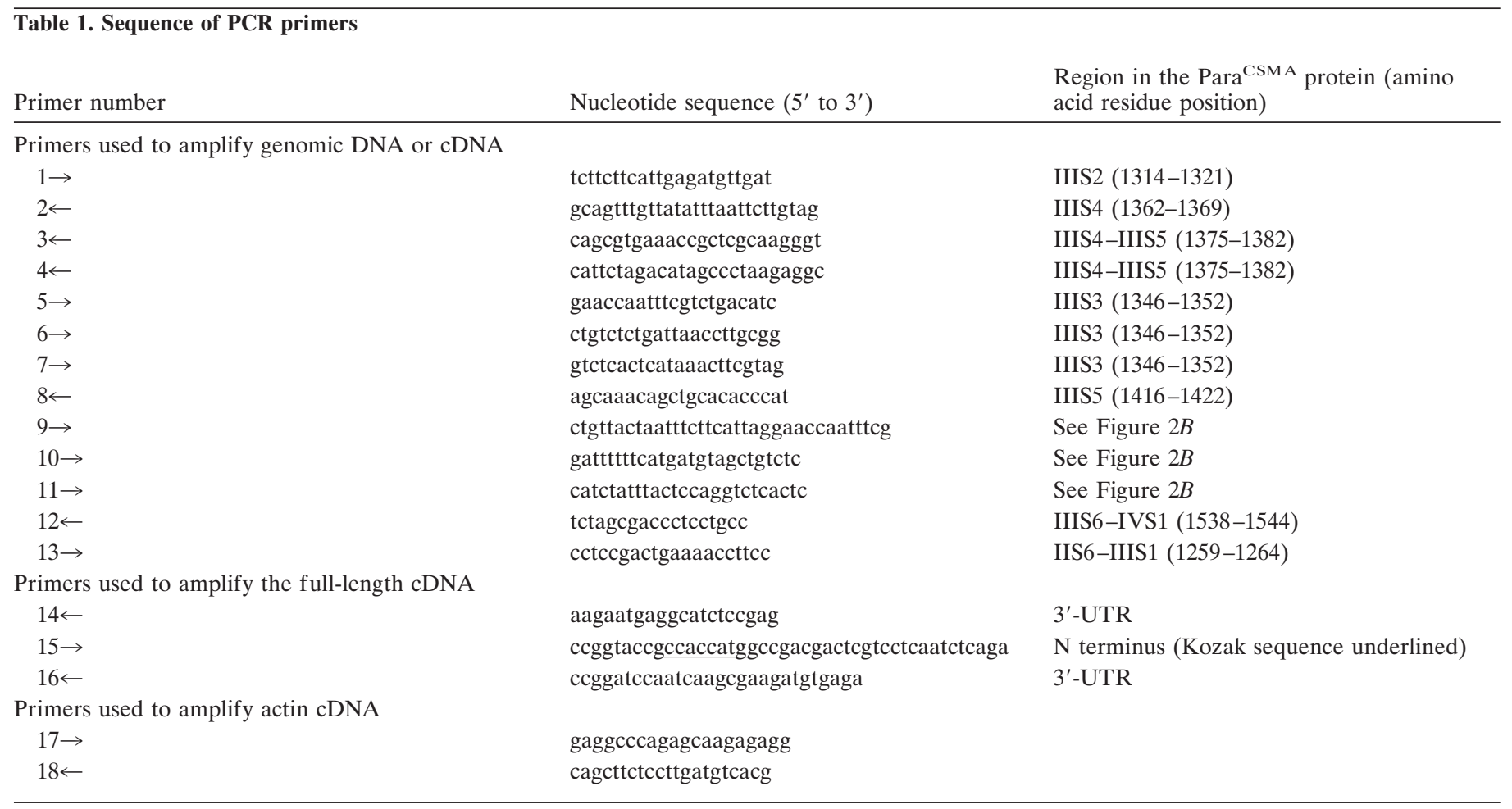

Note: $\rightarrow$ and $\leftarrow$ indicate sense and antisense primers, respectively.

\section{A}

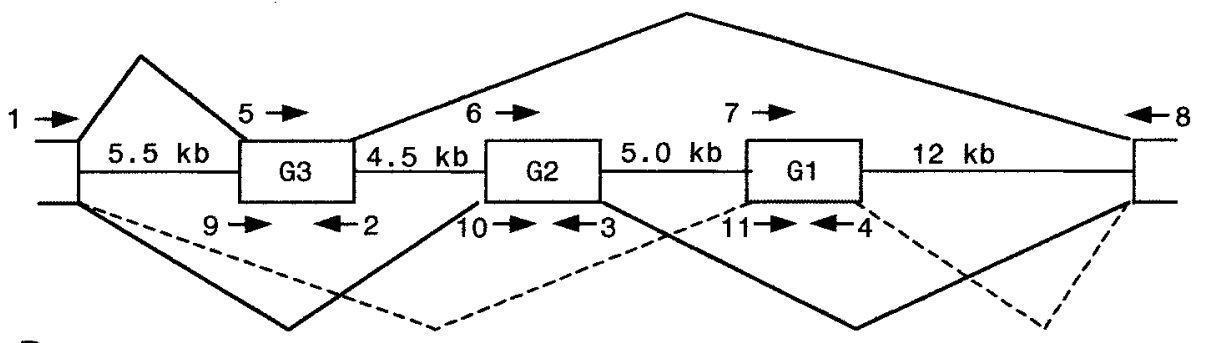

B

Exon $\mathrm{G1}(123 \mathrm{bp})$

- tacatctatt tactccag GTCTCACTCATAAACTTC ... AGAATGCAGGGGATGAGG gtat * $11 \longrightarrow$\begin{tabular}{lllllllllllll}
$V$ & $S$ & $L$ & $I$ & $N$ & $F$ & $\cdots$ & $R$ & $M$ & $Q$ & $G$ & $M$ & $R$ \\
\hline
\end{tabular}

Exon $\mathrm{G2}(123 \mathrm{bp})$

- atgattttttccatgatgtag CTGTCTCTGATTAACCTT . . CGCTGGGAGGGAATGAGA gtaa *

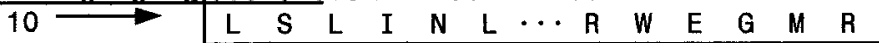

Exon G3 (74bp)

- ttctgttactaatttcttcattagGAACCAATTTCGTCTGAT … TAATATAACAAACTGCG gtgat .

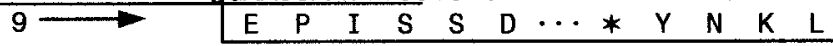

of clone 3 contained a premature in-frame stop codon, which would generate a truncated protein containing only the first two domains (I and II). Localization of clustered sequence differences within a small region (123 bp) suggests an alternative splicing mechanism.

\section{Genomic organization analysis confirms alternative splicing}

If alternative splicing is involved in the generation of the three variable IIIS3-4 regions, we expect to observe three alternatively spliced exon sequences within the $\operatorname{para}^{\text {CSMA }}$ genomic sequence. To test this possibility, we examined the genomic organization of the IIIS3-4 region by sequencing the corresponding genomic DNA. Primers designed based on cDNA sequences were used in PCR amplification of the corresponding genomic sequences (Table 1, Fig. 2). Alignment of the genomic and cDNA sequences revealed three exons, designated $\mathrm{G} 1, \mathrm{G} 2$, and $\mathrm{G} 3$, and four introns connecting exons $\mathrm{G} 1$ and $\mathrm{G} 2$, and G3. (Fig. 2A). The intron-exon boundary sequences are presented in Figure $2 B$. 
The three alternative exons have not been described in D. melanogaster. However, we adopted the exon nomenclature of the $D$. melanogaster para gene in naming these novel exons, except that capital letters were used for cockroach exons.

Sequences of the three exons matched perfectly with the variable regions of the three cDNA clones. Exon G1 corresponded to the 123 bp insert in clone 1; exon G2 corresponded to the $123 \mathrm{bp}$ insert in clone 2; and exon G3 corresponded to the 74 bp insert in clone 3 . The $5^{\prime}$ donor and $3^{\prime}$ acceptor site sequences, gt and ag (Fig. 2B, in bold), respectively, agreed well with the consensus $5^{\prime}$ donor and 3' acceptor site sequences in Drosophila (Mount et al., 1992). Therefore, we conclude that the sequence polymorphism in IIIS3-4 in the three clones is the result of alternative splicing of three mutually exclusive alternative exons.

\section{Isolation of three full-length cDNA clones representing splice variants}

By RT-PCR, we cloned and sequenced three full-length para $^{C S M A}$ cDNA clones (named KD1, KD2, and KD3) that contain exons G1, G2, and G3, respectively. Besides this difference, the three clones differ in the usage of several optional exons in other regions. KD1 contains an insertion of GDFGRRKKKKE at the amino acid position 49. Interestingly, an insertion of GILDGGTIKK at the same location was reported previously by Dong (1997). Both insertions are likely optional exons. Because the location and sequence of this insertion are homologous to that of the exon $j$ in the Drosophila para gene, we designate this optional exon J. KD2 and KD3 lack exon J. KD2 contains an insertion of VPQFRDTKTATKSQFTFAYQENLVK at the amino acid position 534, which was also reported by Dong (1997). The position of this sequence corresponds to that of the exon $i$ in the Drosophila para gene. Therefore it is designated exon I. KD1 and KD3 lack exon I. All three clones lack a sequence reported previously [ ${ }^{727}$ VSIYYFPT ${ }^{735}$ (Dong, 1997)] that corresponds to the exon $b$ in the Drosophila para gene. Furthermore, compared with the previously published sequence of the German cockroach para ${ }^{\text {CSMA }}$ gene (Dong, 1997), there were four scattered amino acid differences in KD1-R502G, L1285P, V1685A, and I1806L, and six scattered amino acid differences in KD2-T743I, D802G, missing G1111, I1299V, H1438Y, and Q1965R. Because KD3 contains a stop codon in IIIS3-4, we only sequenced the insert up to IIIS3-4, and three amino acid differences were detected: P18L, E305G, and L652P. The scattered amino acid differences could represent errors introduced during PCR, alternative splicing, or RNA editing, which has been reported for the Drosophila para gene (Hanrahan et al., 2000; Reenan et al., 2000).

\section{Splice variants exhibit differences in peak current amplitude and gating properties}

The cRNAs from KD1, KD2, and KD3 were expressed in Xenopus oocytes in combination with Drosophila tipE. Sodium currents were detectable in oocytes injected with KD1 and KD2 cRNAs, but no sodium currents were detected from oocytes expressing KD3, even when a fivefold higher amount (5 ng) of cRNA was injected.

The amplitudes of peak sodium current after depolarization from -120 to $-10 \mathrm{mV}$ averaged $0.48 \pm 0.13$ and $1.86 \pm 0.58 \mu \mathrm{A}$ at day 4 for KD1 and KD2 channels, respectively (Fig. 3). Oocytes from different frogs exhibited variability in the level of channel expression, but the sodium current amplitude in oocytes expressing KD2 channels was consistently at least twofold greater than that in oocytes from the same frog expressing KD1 channels.

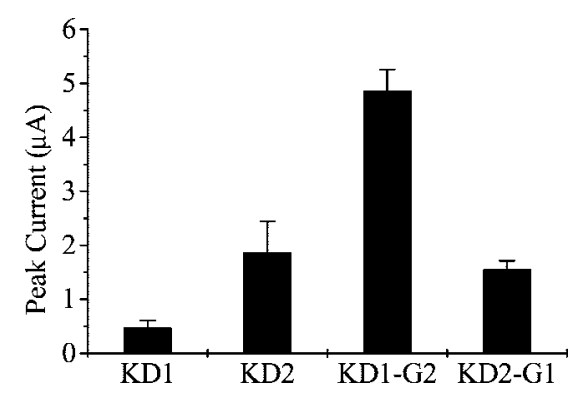

Figure 3. Peak currents of Para ${ }^{\text {CSMA }}$ sodium channel splice variants in oocytes. Amplitude of the maximal peak current was measured during a $20 \mathrm{msec}$ depolarization from -120 to $-10 \mathrm{mV} 4 \mathrm{~d}$ after injection. The error bars indicate the SEM for six oocytes.

Table 2. Voltage-dependence of activation and steady-state inactivation of sodium channel splice variants

\begin{tabular}{llllll} 
& \multicolumn{2}{l}{ Activation } & & Inactivation \\
\cline { 2 - 3 } \cline { 5 - 6 } $\mathrm{Na}^{+}$channel type & $V_{1 / 2}(\mathrm{mV})$ & $k(\mathrm{mV})$ & & $V_{1 / 2}(\mathrm{mV})$ & $k(\mathrm{mV})$ \\
\hline $\mathrm{KD} 1$ & $-23.3 \pm 0.8$ & $5.5 \pm 0.5$ & & $-43.4 \pm 0.8$ & $5.3 \pm 0.3$ \\
$\mathrm{KD} 2$ & $-17.6 \pm 0.4^{a}$ & $5.4 \pm 0.4$ & & $-47.9 \pm 0.8^{a}$ & $4.7 \pm 0.5$ \\
$\mathrm{KD} 1-G 2$ & $-21.2 \pm 0.5^{a}$ & $3.8 \pm 0.2^{a}$ & & $-42.6 \pm 1.1$ & $4.8 \pm 0.2$ \\
$\mathrm{KD} 2-\mathrm{G} 1$ & $-20.4 \pm 0.4^{b}$ & $4.1 \pm 0.2^{b}$ & & $-48.0 \pm 0.7^{b}$ & $5.0 \pm 0.2$
\end{tabular}

The voltage dependence of conductance and inactivation data were fitted with two-state Boltzmann equations, as described in Materials and Methods, to determine $V_{1 / 2}$, the voltage for half-maximal conductance or inactivation, and $k$, the slope factor for conductance or inactivation. Each value represents the mean \pm SD for five oocytes (KD1 and KD2) and four oocytes (KD1-G2 and KD2-G1).

${ }^{a}$ Statistically significant difference compared with KD1 $(p<0.01)$.

${ }^{b}$ Statistically significant difference compared with KD2 $(p<0.01)$.

The currents were completely blocked by 20 nM TTX. No difference in TTX sensitivity was observed between KD1 and KD2 channels (data not shown).

We next examined the voltage dependence of activation and inactivation of KD1 and KD2 channels expressed in Xenopus oocytes (Table 2, Fig. 4). Peak currents were measured at test potentials ranging from $-120 \mathrm{mV}$ to $+60 \mathrm{mV}$ in $5 \mathrm{mV}$ increments. The average relative sodium conductance was calculated as described in Materials and Methods and plotted as a function of depolarizing test potentials (Fig. $4 A$ ). The voltage for halfmaximal activation for KD1 was $\sim 6 \mathrm{mV}$ more negative than that for KD2 (Table 2), with no difference in the slope factor. To determine the voltage dependence of steady-state inactivation, oocytes were held at $-120 \mathrm{mV}$ and depolarized with a series of $200 \mathrm{msec}$ inactivating prepulses from $-120 \mathrm{mV}$ to $+40 \mathrm{mV}$ in 5 $\mathrm{mV}$ increments, each being followed by $12 \mathrm{msec}$ test pulses to -5 $\mathrm{mV}$ to measure channel availability. The voltage dependence of steady-state inactivation was obtained by plotting the normalized peak current as a function of prepulse potentials, as described in Materials and Methods. The voltage for half-maximal inactivation for KD1 was $\sim 6 \mathrm{mV}$ more positive than that for KD2 (Table 2). The slope factor was slightly larger for KD1 compared with KD2.

\section{Differential sensitivity of splice variants to a pyrethroid insecticide, deltamethrin}

To determine whether KD1 and KD2 differ in sensitivity to deltamethrin, deltamethrin-induced tail currents were recorded 5 min after application of deltamethrin at each concentration. After the repolarization of KD1, a large hooked tail current was induced by deltamethrin at a concentration of $1.0 \mu \mathrm{M}$. The tail 

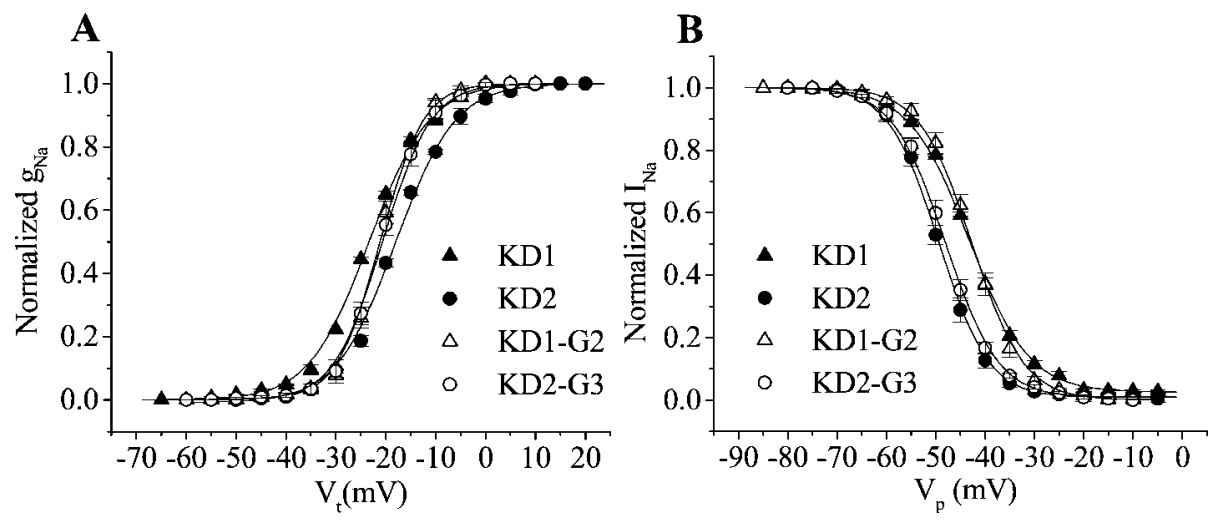

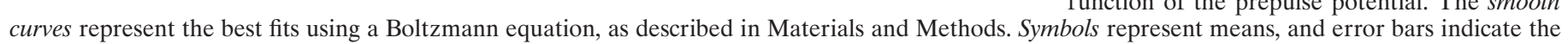
SEM for four oocytes.

current decayed slowly with a time constant of $1450 \pm 335 \mathrm{msec}$, and the current did not decay to the baseline by the end of the 8 sec recording time (Fig. $5 A$ ). Concentrations $>1.0 \mu \mathrm{M}$ resulted in large leakage currents that made it impossible to clamp the oocytes. In contrast, much higher concentrations of deltamethrin $(10-100 \mu \mathrm{M})$ were required to elicit significant tail currents for $\mathrm{KD} 2$. In addition, the tail currents for KD2 decayed rapidly with a time constant of $504 \pm 81 \mathrm{msec}$, returning to the baseline within $3 \mathrm{sec}$ (Fig. 5B). The percentage of channel modification was quantified using the equation described in Materials and Methods. Approximately 100-fold more deltamethrin was required to modify an equivalent percentage of KD2 channels compared with KD1 channels (Fig. 5E). Therefore, KD1 and KD2 exhibit strikingly different sensitivities to deltamethrin.

\section{Alternative exons G1 and G2 modulate channel gating and sensitivity to deltamethrin}

To examine whether exons G1 and G2 contribute to the observed differences in peak current, channel gating properties, and sensitivity to deltamethrin, we produced the following two recombinant constructs, KD1-G2 and KD2-G1, in which exons G1 and G2 were switched. The two recombinant channels were expressed in oocytes, and their peak current amplitudes and gating properties were compared with those of the parental channels. As described above, the sodium current amplitude of KD2 was approximately twofold greater than that of KD1. We found that this current amplitude difference was determined primarily by alternative exons G1/G2. Specifically, we observed a 10-fold increase in the peak current amplitude of KD1-G2 compared with that of KD1 (Fig. 3), whereas KD2-G1 had approximately a fivefold lower level of peak current amplitude compared with KD2. Therefore, the alternative exons G1/G2 are a major contributor in modulating sodium current amplitude.

Oocytes exhibiting the peak current amplitude of $\sim 2 \mu \mathrm{A}$ were used for recording channel properties and tail current. Therefore, the recording for KD1-G2 was usually done 2-3 d earlier than KD2-G1. The voltage dependence of activation was also affected by exons G1/G2 (Table 2, Fig. 4). Compared with KD1, KD2 exhibited a $6 \mathrm{mV}$ depolarizing shift in the voltage dependence of activation. The activation curve for KD1-G2 was shifted in the depolarizing direction by $2 \mathrm{mV}$ compared with KD1, whereas the activation curve for KD2-G1 was shifted in the hyperpolarizing direction by $2 \mathrm{mV}$ compared with that of KD2. The slope values were reduced by $1.5 \mathrm{mV}$ for the exon-swapped channels compared with those for the two parental channels. Therefore, alternative
Figure 4. Voltage dependence of activation and inactivation of Para ${ }^{\text {CSMA }}$ splice variants. $A$, Normalized conductance-voltage curves. Sodium currents were recorded during $14 \mathrm{msec}$ depolarizations ranging from -120 to $60 \mathrm{mV}$ in $5 \mathrm{mV}$ increments. The peak current was converted to conductance as described in Materials and Methods and plotted against the depolarizing voltage. $B$, Steady-state inactivation curves. The voltage dependence of inactivation was determined using $200 \mathrm{msec}$ inactivating prepulses from a holding potential of -120 to $+40 \mathrm{mV}$ in $5 \mathrm{mV}$ increments, followed by test pulses to -5 $\mathrm{mV}$ for 5 msec. The peak current amplitude during the test depolarization was normalized to the maximum current amplitude and plotted as a function of the prepulse potential. The smooth $V_{p}(\mathrm{mV})$ exons G1/G2 are partially responsible for the difference in the voltage dependence of channel activation. In contrast, there was no significant difference in steady-state inactivation between KD1-G2 and KD1, or between KD2-G1 and KD2, suggesting that alternative exons G1 and G2 are not involved in the difference in the steady-state inactivation between KD1 and KD2.

We next determined whether alternative exons G1 and G2 are involved in the differential sensitivities of KD1 and KD2 to deltamethrin. Introduction of exon G1 into the KD2 channel resulted in a significant increase in the sensitivity to deltamethrin by 10 -fold (Fig. $5 D$ ). Consistent with this result, introduction of exon $\mathrm{G} 2$ into the KD1 channel reduced the sensitivity by 10 -fold for the KD1 channel (Fig. $5 C$ ). Therefore, exons G1 and G2 contribute significantly to the differential sensitivities of KD1 and KD2 to deltamethrin.

Because KD1 and KD2 contain optional exons J and I, respectively, we therefore examined a possible role of exons $\mathrm{J}$ and $\mathrm{I}$ in the functional and pharmacological differences between KD1 and KD2. For this purpose, we produced two additional recombinant Para ${ }^{\text {CSMA }}$ constructs with exons J and I swapped between KD1 and KD2. A $1.6 \mathrm{~kb} \mathrm{KpnI/AccI}$ fragment (corresponding to the $\mathrm{N}$ terminus up to $\mathrm{S}^{538}$ ), which includes exon $\mathrm{J}$ in KD1 and exon $\mathrm{I}$ in $\mathrm{KD}$ 2, was excised from the parental constructs and swapped to generate two chimeric constructs, KD1-I and KD2-J. However, no significant difference was detected in current amplitude, gating properties, or deltamethrin sensitivity between KD1 and KD1-I or between KD2 and KD2-J (data not shown). These results demonstrated that exons $\mathrm{J}$ and $\mathrm{I}$ are not involved in any of the observed property and pharmacological differences between KD1 and KD2 and suggested a role of the remaining 10 scattered amino acid differences between KD1 and KD2 in modulating channel properties.

\section{Tissue distribution of splicing variants}

In a previous study, we detected the para ${ }^{\text {CSMA }}$ transcript in nerve cords and legs and in all developmental stages of German cockroaches using a pair of primers amplifying the 3 'end of the para $^{\text {CSMA }}$ gene (Liu et al., 2001). Because the splice variants have different functional and pharmacological properties, it seemed likely that they might be expressed in a tissue- or developmentspecific manner. To test this possibility, RT-PCR using exonspecific primers was performed to examine the expression patterns of the three confirmed splice variants at various developmental stages and in several tissues, including nerve cord, leg, gut, and ovary. Primers 13 and 4 (Table 1) amplified a 385 bp 


\section{A KD1}

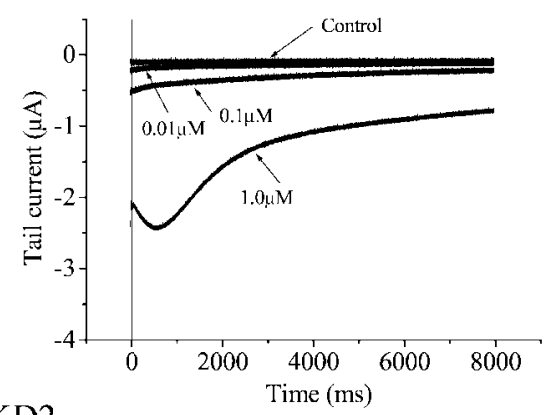

B $\mathrm{KD} 2$

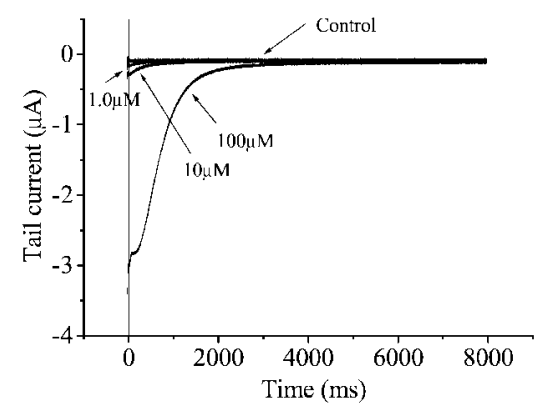

C KD1-G2

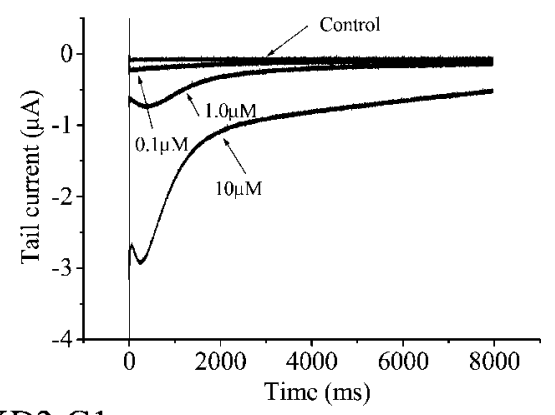

\section{KD2-G1}

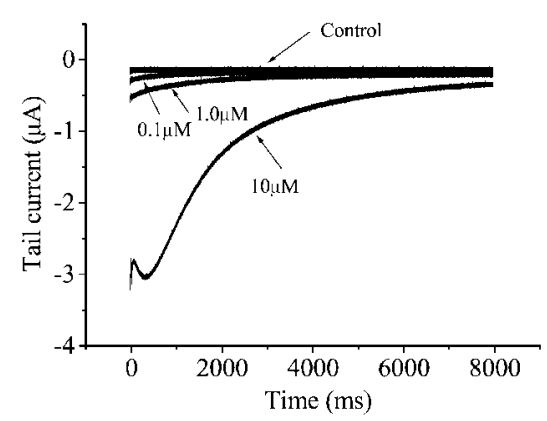

$\mathrm{E}$

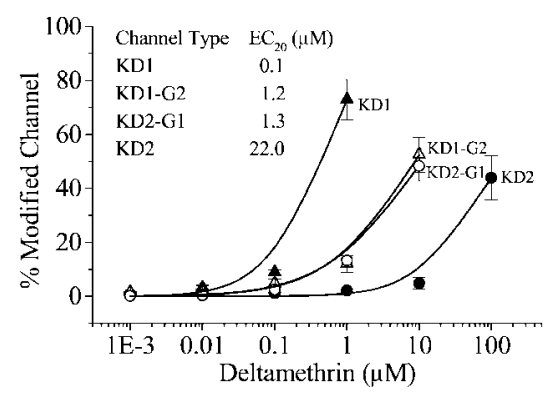

Figure 5. Sensitivity of Para ${ }^{\text {CSMA }}$ splice variants to deltamethrin. Shown are tail currents induced by deltamethrin in oocytes expressing the splice variants $\mathrm{KD} 1(A)$ and $\mathrm{KD} 2(B)$ and the exon-swapped channels, KD1-G2 $(C)$ and KD2-G1 $(D)$. Tail currents were recorded in response to a 100-pulse train of $5 \mathrm{msec}$ depolarizations from -100 to $0 \mathrm{mV}$ with a 5
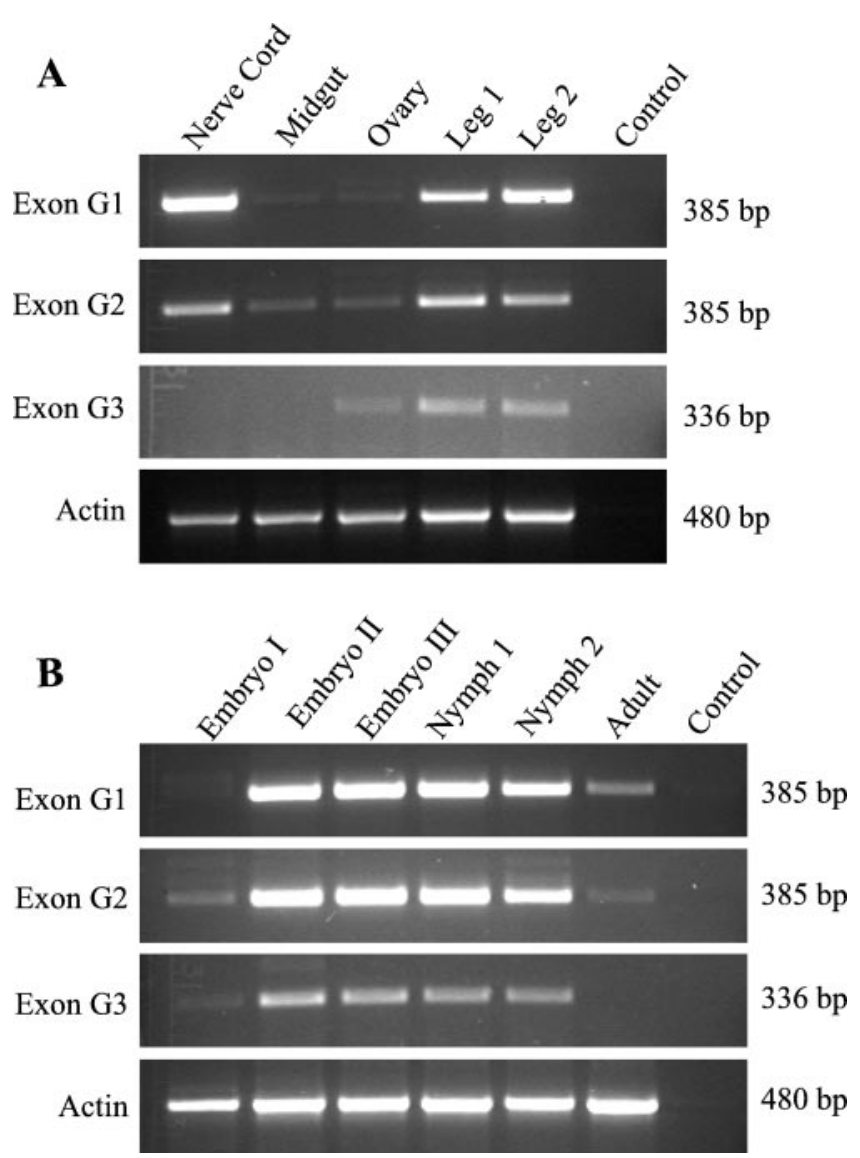

Figure 6. RT-PCR analysis of splice variants in five tissues $(A)$ and six developmental stages $(B)$. Equal amounts of total RNA $(5 \mu \mathrm{g})$ were used in cDNA synthesis, and equal amounts of cDNA templates $(1 \mu \mathrm{l})$ were used in PCR. Amplification of actin (480 bp) is included to ensure that similar amounts of RNA and cDNA were used in RT-PCR for the various tissues and developmental stages. Each PCR product $(10 \mu \mathrm{l})$ was separated on a $1.5 \%$ agarose gel. The criteria for classification of the developmental stages and tissues are described in Materials and Methods.

fragment containing exon G1, primers 13 and 3 amplified a 385 bp fragment containing exon G2, and primers 13 and 2 amplified a 336 bp fragment containing exon G3 (Fig. 6). The transcript carrying exon G1 was abundantly expressed in nerve cord and leg 1 and leg 2. The transcript carrying exon G2 was also expressed in nerve cord and leg 1 and leg 2 . Interestingly, low-level expression of exon $\mathrm{G} 2$ was also detected in ovary and gut. The transcript containing exon G3, which possesses a stop codon, was not detected in nerve cord but was detected in leg 1, leg 2, and ovary. Therefore, the three splicing variants exhibited distinct tissue expression patterns. In contrast, no apparent stage-specific expression of the variants was observed (Fig. 6). All three variants were abundantly expressed in embryonic stages II and III and the

$\leftarrow$

msec interval between each depolarization. $E$, The percentage of channel modification by deltamethrin was determined using the equation $M=$ $\left\{\left[I_{\text {tail }} /\left(E_{\mathrm{h}}-E_{\mathrm{Na}}\right)\right] /\left[I_{\mathrm{Na}} /\left(\mathrm{E}_{\mathrm{t}}-E_{\mathrm{Na}}\right)\right]\right\} \times 100$, as described in Materials and Methods (Tatebayashi and Narahashi, 1994). The data were fitted with the Hill equation as described in Materials and Methods. $\mathrm{EC}_{20}$ values (inset) were derived from the fitted curves. The Hill coefficients range from 0.8 to 1.4. Symbols represent means, and error bars indicate the SEM for five oocytes. 
two nymphal stages, but they exhibited much lower levels of expression in adults compared with the immature stages.

\section{DISCUSSION}

In this study we found that the cockroach para ${ }^{\text {CSMA }}$ sodium channel gene contains alternatively spliced variants that have apparently been preserved for more than 500 million years, since the evolutionary divergence of vertebrates and invertebrates. Alternative splicing produces two functional sodium channels with distinct electrophysiological properties and sensitivity to deltamethrin as well as an apparently nonfunctional two-domain channel protein. Using exon swapping, we determined that the alternative exons $\mathrm{G} 1 / \mathrm{G} 2$ are directly involved in modulating sodium current amplitude, voltage dependence of channel activation, and channel sensitivity to a pyrethroid. Our findings thus provide direct evidence for the generation of sodium channel functional and pharmacological diversity by alternative splicing.

\section{Conservation of the G1/G2/G3 splice site among vertebrate and invertebrate species}

The exon-intron arrangement in the IIIS3-4 region of the cockroach gene is similar to that of the mouse SCN8A gene encoding Nav1.6 and the orthologous genes in humans and fish (Plummer et al., 1997). The two alternatively spliced exons of the mouse SCN8A gene (named 18N and 18A) are interrupted by a $353 \mathrm{bp}$ intron. Exon $18 \mathrm{~N}$ is similar to the cockroach exon G3, having an in-frame stop codon that generates a truncated protein containing only the first two domains. The length of the variable region is exactly $123 \mathrm{bp}$ in both mouse and cockroach, and the amino acid sequences at the ends of mouse exons $18 \mathrm{~A} / 18 \mathrm{~N}$ correspond exactly to those of the cockroach exons G1/2/3. The key difference between the cockroach and mouse sodium channel proteins is the presence of three mutually exclusive exons in cockroach $(\mathrm{G} 1 / 2 / 3)$, but only two exons in vertebrate counterparts $(18 \mathrm{~A} / \mathrm{N})$, suggesting that there was a loss of one exon during evolution from insects to vertebrates. Alternatively, it is possible that vertebrates do have all three alternative exons and that the third one has not yet been identified.

The presence of the two-domain sodium channel proteins in both invertebrates and vertebrates suggests a conserved biological function. However, we did not detect any sodium current in Xenopus oocytes injected with cRNA encoding this variant, suggesting that this splice variant does not function as a normal sodium channel. It is possible that the two-domain proteins interact with other proteins such as their full-length counterparts to modulate or eliminate sodium channel activity in specific cells. In this regard, it is interesting to note that the cockroach twodomain splice variant (KD3) has a unique tissue-specific expression pattern. Its transcript was detected in only legs and ovary and not in nerve cords, in contrast to the two functional splice variants, which were detected in nerve cords and legs. The mouse counterpart of KD3, SCN8A-18N, also has a unique expression pattern. It is expressed in non-neuronal tissues such as liver, kidney, stomach, spleen, thymus, and testis (Plummer et al., 1997). Therefore, it appears that specific tissues in both invertebrate and vertebrate animals are programmed to regulate the alternative splicing events at this site.

There are examples of other four-domain ion channel genes producing two-domain variants by alternative splicing. For example, a two-domain isoform of a major skeletal muscle $\mathrm{Ca}^{2+}$ channel $\alpha$-subunit is abundantly expressed in newborn rabbit muscle (Malouf et al., 1992). Two splice variants of the cockroach
BSC1 channel protein, an ortholog of the D. melanogaster DSC1 channel protein, contain either in-frame or out-of-frame stop codons in the linker region connecting domains II and III, resulting in truncated two-domain proteins (Liu et al., 2001). Like the two-domain KD3 sodium channel protein, the truncated BSC1 protein is expressed exclusively in cockroach leg (Liu et al., 2001). Therefore, generation of two-domain variants of four-domain channel proteins appears to be an evolutionarily conserved mechanism for the regulation of ion channels in animals.

\section{Alternative splicing generates sodium channel diversity}

The functional significance of alternative splicing in generating ion channel diversity was first demonstrated for $\mathrm{K}^{+}$channels encoded by the Drosophila Shaker locus (Iverson et al., 1988; Timpe et al., 1988). The alternatively spliced transcripts of the Shaker gene share a central core and differ at their N- and $\mathrm{C}$-terminal ends. These splice variants produce transient A-type $\mathrm{K}^{+}$currents with distinct activation and inactivation kinetics (Iverson et al., 1988; Timpe et al., 1988). Functional differences resulting from alternative splicing were also observed for the Drosophila Slowpoke gene, which encodes a calcium-activated potassium channel (Lagrutta et al., 1994). Splice variants of Slowpoke differ in unit conductance, gating kinetics, and calcium sensitivity (Lagrutta et al., 1994). A third example of alternative splicing leading to functional diversity involves $\mathrm{Ca}^{2+}$ channels, in which functionally distinct splice variants are selectively expressed in different regions of the rat nervous system (Lin et al., 1997, 1999). Therefore, regulated alternative splicing appears to be an important mechanism for generating functionally diverse ion channels in different tissues or cell types.

The existence of sodium channel functional diversity was reported in cultured insect neurons. For example, fast and completely inactivating sodium currents were observed in some $D$. melanogaster neurons, whereas other neurons exhibited a noninactivating component (Saito and $\mathrm{Wu}, 1991)$. In addition, there is significant variation in the amplitude of peak current in Drosophila embryonic neurons (Byerly and Leung, 1988). The molecular basis of this diversity was not understood before this study. Our finding of the difference in sodium current amplitudes, the voltage dependence of activation, and pyrethroid sensitivity between the German cockroach KD1 and KD2 splice variants clearly shows that alternative splicing can effectively generate sodium channel diversity in insects. Although the G1/G2/G3 alternative exons were discovered first in German cockroaches, they are likely present in D. melanogaster and other insects. For example, the functionally expressed $D$. melanogaster para cDNA clone apparently contains exon G1 (Loughney et al., 1989), whereas the functionally expressed para ortholog of the house fly (Vssc1) contains exon G2 (Ingles et al., 1996). These two channels exhibit distinct gating properties when expressed in Xenopus oocytes (Smith et al., 1997; Warmke et al., 1997). On the basis of our results, it is possible that the observed differences could be attributable in part to the different alternative exons contained in the D. melanogaster and house fly cDNA clones used in these studies.

The mechanism by which the two alternative splice variants differ in the peak current amplitude is not known. The two variants could differ in the folding or assembly of the Para CSMA protein, which would result in fewer or more functional channels, or they differ in either the single channel conductance or probability of channel opening, or they differ in the interaction between 
Para ${ }^{\text {CSMA }}$ with TipE, which is required for robust expression in oocytes. These possibilities require further investigation.

Interestingly, the functional differences between the KD1 and KD2 splice variants are strikingly reminiscent of the mammalian sodium channel isoforms produced by distinct genes. For example, the Nav1.6 channel activates at a more positive membrane potential and displays a hyperpolarizing shift in the voltage dependence of steady-state inactivation compared with the Nav1.1 and Nav1.2 channels (Smith et al., 1998), similar to the KD2 splice variant compared with KD1. Therefore, alternative splicing of a single gene transcript appears to be a major mechanism by which insects generate sodium channel functional diversity, whereas vertebrates have evolved a distinct mechanism involving selective expression of multiple sodium channel genes.

\section{Alternative splicing generates sodium channels with distinct pharmacological properties}

It is known that mammalian sodium channel isoforms encoded by different genes display different sensitivities to various neurotoxins. For example, most mammalian sodium channels are blocked by nanomolar concentrations of TTX, but some, such as the Nav1.5 cardiac muscle sodium channel and the Nav1.8 PNS sodium channel, require micromolar concentrations for block (Goldin, 1999). Sodium channel isoforms also exhibit differential sensitivity to pyrethroid insecticides. TTX-sensitive sodium channels in the rat dorsal root ganglion neurons are less sensitive to pyrethroid insecticides than TTX-resistant sodium channels in the same neurons (Ginsburg and Narahashi, 1993; Tatebayashi and Narahashi, 1994; Song and Narahashi, 1996; Tabarean and Narahashi, 1998). Rat Nav1.2 and Na1.4 channels are much less sensitive to pyrethroids (Vais et al., 1997; Warmke et al., 1997; Smith and Soderlund, 1998; Wang et al., 2001), whereas rat Nav1.8 sodium channels are sensitive to pyrethroids (Soderlund et al., 2000). However, alternative splicing has not been implicated in any of the different toxin responses before this study. In insects, early electrophysiological studies showed that the sensitivity of the insect nervous system to pyrethroids varies greatly depending on nerve preparations, suggesting the presence of distinct subtypes of sodium channels (Burt and Goodchild, 1971; Miller and Adams, 1977; Osborne and Hart, 1979; Salgado et al., 1983; Roche and Guillet ,1985). For example, permethrin (a pyrethroid insecticide) affects the insect sensory neurons more profoundly than the neuromuscular synapses (Osborne and Hart, 1979). The differential sensitivity to deltamethrin between two cockroach splice variants, KD1 and KD2, therefore provides direct evidence for a functional role of alternative splicing in the generation of sodium channel pharmacological diversity in insects.

Whether the differential sensitivity to deltamethrin between KD1 and KD2 channels is mechanistically linked to the differences in the channel gating properties is not clear. Point mutations in S6 of domains I, II, and III are identified to reduce sodium channel sensitivity to pyrethroids (Smith et al., 1997; Vais et al., 2000; Z hao et al., 2000; Lee and Soderlund, 2001; Wang et al., 2001; Liu et al., 2002; Tan et al., 2002). Because the sixth segments of each domain likely situate in close physical proximity in the completely folded channel, the corresponding amino acid residues may be spatially close to each other, constituting a pyrethroid-binding site or a pyrethroid-response domain (Lee and Soderlund, 2001; Liu et al., 2002). Formation of a binding site by amino acid residues in S6 of several distinct domains has also been proposed for several classes of lipophilic neurotoxins that act on calcium and sodium channels (Hockerman et al., 1997; Linford et al., 1998). We did not observe any significant difference in the rate of inactivation among KD1 and KD2 channels (data not shown). Whether IIIS3-4 is part of a pyrethroid binding site or it alters the gating properties, which in turn alters the interaction between the sodium channel and deltamethrin, remains to be investigated.

Although our data clearly show an involvement of the alternative exons G1/G2 in modulating sodium channel gating properties, peak current, and interaction with pharmacological agents, they also implicate an involvement of additional amino acid changes. Specifically, exon swapping between exons G1 and G2 did not completely reverse the differences in gating properties and pyrethroid sensitivity between KD1 and KD2, and exon swapping between exons $\mathrm{J}$ and I had no effect. We therefore must conclude that the 10 additional scattered amino acid differences between KD1 and KD2 outside of exons G1/G2, J, and I are responsible for the residual differences between KD1 and KD2. None of the scattered amino acid differences occurs in the regions that are homologous to identified alternative splice exons in the Drosophila para gene. The scattered nature of these amino acid differences can be best explained by RNA editing or PCR errors, although additional alternative splicing events cannot be excluded. Future site-directed mutagenesis and functional analysis are required to determine which of these 10 amino acid differences outside of the identified alternative and optional exons are involved in splice variant-specific gating and pharmacological properties.

\section{REFERENCES}

Belcher SM, Zerillo CA, Levinson R, Ritchie JM, Howe JR (1995) Cloning of a sodium channel $\alpha$-subunit from rabbit Schwann cells. Proc Natl Acad Sci USA 92:11034-11038.

Bell WL (1981) The laboratory cockroach. New York: Chapman and Hall.

Bourinet E, Soong TW, Sutton K, Slaymaker S, Mathews E, Monteil A, Zamponi GW, Nargeot J, Snutch TP (1999) Splicing of alpha 1A subunit gene generates phenotypic variants of P- and Q. Nat Neurosci 2:407-415.

Burt PE, Goodchild RE (1971) The site of action of pyrethrin I in the nervous system of the cockroach Periplaneta Americana. Ent Exp Appl 14:179-189.

Byerly L, Leung H (1988) Ionic currents of Drosophila neurons in embryonic cultures. J Neurosci 8:4379-4393.

Catterall WA (2000) From ionic currents to molecular mechanisms: the structure and function of voltage-gated sodium channels. Neuron 26:13-25.

Dietrich PS, McGivern JG, Delgado SG, Koch BD, Eglen RM, Hunter JC, Sangameswaran L (1998) Functional analysis of a voltage-gated sodium channel and its splice variant from rat dorsal root ganglia. J Neurochem 70:2262-2272.

Dong K (1997) A single amino acid change in the Para sodium channel protein is associated with knockdown-resistance $(k d r)$ to pyrethroid insecticides in German cockroach. Insect Biochem Mol Biol 27:93-100.

Dong K, Scott JG (1994) Linkage of $k d r$-type resistance and the parahomologous sodium channel gene in the German cockroach (Blattella germanica). Insect Biochem Mol Biol 24:647-654.

Feng G, Deak P, Chopra M, Hall LM (1995) Cloning and functional analysis of TipE, a novel membrane protein that enhances Drosophila Para sodium channel function. Cell 82:1001-1011.

Ginsburg KS, Narahashi T (1993) Differential sensitivity of tetrodotoxin-sensitive and tetrodotoxin-resistant sodum channels to the insecticide allethrin in rat dorsal root ganglion neurons. Brain Res 627:239-248

Goldin AL (1992) Maintenance of Xenopus laevis and oocyte injection. Methods Enzymol 207:266-279.

Goldin AL (1999) Diversity of mammalian voltage-gated sodium channels. Ann NY Acad Sci 868:38-50.

Goldin AL (2001) Resurgence of sodium channel research. Annu Rev Physiol 63:871-894.

Gustafson TA, Clevinger EC, O'Neill TJ, Yarowsky PJ, Krueger BK (1993) Mutually exclusive exon splicing of type III brain sodium channel alpha subunit RNA generates developmentally regulated isoforms in rat brain. J Biol Chem 268:18648-18653.

Hanrahan CJ, Palladino MJ, Ganetzky B, Reenan RA (2000) RNA 
editing of the Drosophila para $\mathrm{Na}^{+}$channel transcript: evolutionary conservation and developmental regulation. Genetics 155:1149-1160.

Hockerman GH, Perterson BZ, Johnson BD, Catterall WA (1997) Molecular determinants of drug binding and action of L-type calcium channels. Annu Rev Pharmacol Toxicol 37:361-396.

Ingles PJ, Adams PM, Knipple DC, Soderlund DM (1966) Characterization of voltage-sensitive sodium channel gene coding sequences from insecticides-susceptible and knockdown-resistant house fly strains. Insect Biochem Mol Biol 26:319-326.

Iverson LE, Tanouye MA, Lester HA, Davidson N, Rudy B (1988) A-type potassium channels expressed from Shaker locus cDNA. Proc Natl Acad Sci USA 85:5723-5727.

Kontis KJ, Goldin AL (1993) Site-directed mutagenesis of the putative pore region of the rat IIA sodium channel. Mol Pharmacol 43:635-644.

Lagrutta A, Shen KZ, North RA, Adelman JP (1994) Functional differences among alternatively spliced variants of Slowpoke, a Drosophila calcium-activated potassium channel. J Biol Chem 32:20347-20351.

Lee SH, Soderlund DM (2001) The V410M mutation associated with pyrethroid resistance in Heliothis virescens reduces the pyrethroid sensitivity of house fly sodium channels expressed in Xenopus oocytes. Insect Biochem Mol Biol 31:19-29.

Lin Z, Haus S, Edgerton J, Lipscombe D (1997) Identification of functionally distinct isoforms of the N-type $\mathrm{Ca}^{2+}$ channel in rat sympathetic ganglia and brain. Neuron 18:153-166.

Lin Z, Lin Y, Schorge S, Pan JQ, Beierlein M, Lipscombe D (1999) Alternative splicing of a short cassette exon in alpha1B generates functionally distinct $\mathrm{N}$-type calcium channels in central and peripheral neurons. J Neurosci 19:5322-5331.

Linford NJ, Cantrell AR, Qu Y, Scheuer T, Catterall WA (1998) Interaction of batrachotoxin with the local anesthetic receptor site in transmembrane segment IVS6 of the voltage-gated sodium channel. Proc Natl Acad Sci USA 95:13947-13952.

Liu Z, Chung I, Dong K (2001) Alternative splicing of the BSC1 gene generates tissue-specific isoforms in the German cockroach. Insect Biochem Mol Biol 31:703-713.

Liu Z, Tan J, Valles SM, Dong K (2002) Synergistic interaction between two cockroach sodium channel mutations and a tobacco budworm sodium channel mutation in reducing channel sensitivity to a pyrethroid insecticide. Insect Biochem Mol Biol 32:397-404.

Loughney K, Kreber R, Ganetzky B (1989) Molecular analysis of the para locus, a sodium channel gene in Drosophila. Cell 58:1143-1154.

Malouf NN, McMahon DK, Hainsworth CN, Kay BK (1992) A twomotif isoform of the major calcium channel subunit in skeletal muscle. Neuron 8:899-906.

Miller TA, Adams ME (1977) Central vs. peripheral action of pyrethroids on the house fly nervous system. In: Synthetic pyrethroids (Elliott M, ed), ACS Symposium Series, Vol 42, pp 98-115. Washington, DC: American Chemical Society.

Mount SM, Burks C, Hertz G, Stormo GD, White O, Fields C (1992) Splicing signals in Drosophila: intron size, information content, and consensus sequences. Nucleic Acids Res 20:4255-4262.

Narahashi T (1988) Molecular and cellular approaches to neurotoxicology: past, present and future. In: Neurotox '88: molecular basis of drug and pesticide action (Lunt GG, ed), pp 563-582. New York: Elsevier.

O'Dowd DK, Gee JR, Smith MA (1995) Sodium current density correlates with expression of specific alternatively spliced sodium channel mRNAs in single neurons. J Neurosci 15:4005-4012.

Osborne MP, Hart RJ (1979) Neurophysiological studies of the effects of permethrin upon pyrethroid resistant $(k d r)$ and susceptible strains of dipteran larvae. Pestic Sci 20:100-114.

Plummer NW, McBurney MW, Meisler MH (1997) Alternative splicing of the sodium channel SCN8A predicts a truncated two-domain protein in fetal brain and non-neuronal cells. J Biol Chem 272:24008-24015.

Reenan RA, Nanrahan CJ, Ganetzky B (2000) The mle napts RNA helicase mutation in Drosophila results in a splicing catastrophe of the para $\mathrm{Na}^{+}$channel transcript in a region of RNA editing. Neuron 25:139-149.

Roche M, Guillet JC (1985) Effects of the pyrethroids bioallethrin, deltamethrin and RU-15525 on the electrical activity of a cuticular mechanoreceptor of the cockroach Periplaneta Americana. Pest Sci 16:511519.

Saito M, Wu CF (1991) Expression of ion channels and mutational effects in giant Drosophila neurons differentiated from cell divisionarrested embryonic neuroblasts. J Neurosci 11:2135-2150.

Salgado VL, Irving SN, Miller TA (1983) The importance of nerve terminal depolarization in pyrethroid poisoning of insects. Pestic Biochem Physiol 20:169-182.

Salkoff L, Butler A, Wei A, Scavarda N, Giffen K, Ifune C, Goodman R, Mandel G (1987) Genomic organization and deduced amino acid sequence of a putative sodium channel gene in Drosophila. Science 237:744-749.

Sarao R, Gupta SK, Auld VJ, Dunn RJ (1991) Developmentally reguated alternative RNA splicing of rat brain sodium channel mRNAs. Nucleic Acids Res 19:5673-5679.

Schaller KL, Krzemien DM, McKenna NM, Caldwell JH (1992) Alternatively spliced sodium channel transcripts in brain and muscle. J Neurosci 12:1370-1381.

Smith MR, Smith RD, Plummer NW, Meisler MH, Goldin AL (1998) Functional analysis of the mouse Scn8a sodium channel. J Neurosci 18:6093-6102.

Smith TJ, Soderlund DM (1998) Action of the pyrethroid insecticide cypermethrin on rat brain IIa sodium channels expressed in Xenopus oocytes. Neurotoxicology 19:823-832.

Smith TJ, Lee SH, Ingles PJ, Knipple DC, Soderlund DM (1997) The L1014F point mutation in the house fly Vssc1 sodium channel confers knockdown resistance to pyrethroids. Insect Biochem Mol Biol 27:807812 .

Soderlund DM, Smith TJ, Lee SH (2000) Differential sensitivity of sodium channel isoforms and sequence variants to pyrethroid insecticides. Neurotoxicology 21:127-138.

Song JH, Narahashi T (1998) Differential effects of pyrethroid tetramethrin on tetrodotoxin-sensitive and tetrodotoxin-resistant single sodium channels. Brain Res 712:258-264.

Tabarean IV, Narahashi T (1998) Potent modulation of tetrodotoxinsensitive and tetrodotoxin-resistant sodium channels by the type II pyrethroid deltamethrin. J Pharmacol Exp Ther 284:958-965.

Tan J, Liu Z, Tsai TD, Valles SM, Goldin AL, Dong K (2002) Novel sodium channel gene mutations in Blattella germanica reduce the sensitivity of expressed channels to deltamethrin. Insect Biochem Mol Biol 32:445-454

Tatebayashi H, Narahashi T (1994) Differential mechanism of action of the pyrethroid tetramethrin on tertodotoxin-sensitive and tetrodotoxinresistant sodium channels. J Pharmacol Exp Ther 270:595-603.

Thackeray JR, Ganetzky B (1994) Developmentally regulated alternative splicing generates a complex array of Drosophila para sodium channel isoforms. J Neurosci 14:2569-2578.

Thackeray JR, Ganetzky B (1995) Conserved alternative splicing patterns and splicing signals in the Drosophila sodium channel gene para. Genetics 141:203-214.

Timpe LC, Jan YN, Jan LY (1988) Four cDNA clones from the Shaker locus of Drosophila induce kinetically distinct A-type potassium currents in Xenopus oocytes. Neuron 1:659-667.

Vais H, Williamson MS, Hick CA, Eldursi N, Devonshire AL, Usherwood PNR (1997) Functional analysis of a rat sodium channel carrying a mutation for insect knockdown resistance $(k d r)$ to pyrethroids. FEBS Lett 413:327-332.

Vais H, Williamson MS, Goodson SJ, Devonshire AL, Warmke JW, Usherwood PNR, Cohen C (2000) Activation of Drosophila sodium channels promotes modification by deltamethrin: reductions in affinity caused by knock-down resistance mutations. J Gen Physiol 115:305-318

Wang S-Y, Barile M, Wang GK (2001) A phenylalanine residue at segment D3-S6 in Nav1.4 voltage-gated $\mathrm{Na}^{+}$channels is critical for pyrethroid action. Mol Pharmacol 68:620-628.

Warmke JW, Reenan RAG, Wang P, Qian S, Arena JP, Wang J, Wunderler D, Liu K, Kaczorowski GJ, Van der Ploeg LHT, Ganetzky B, Cohen CJ (1997) Functional expression of Drosophila para sodium channels: modulation by the membrane protein tipE and toxin pharmacology. J Gen Physiol 110:119-133.

Zhao Y, Park Y, Adams ME (2000) Functional and evolutionary consequences of pyrethroid resistance mutations in S6 transmembrane segments of a voltage-gated sodium channel. Biochem Biophys Res Commun 278:516-521. 